\title{
Perceptions regarding Genetic Testing in Populations at Risk for Nephropathy
}

\author{
Barry I. Freedman ${ }^{a} \quad$ Alison J. Fletcher ${ }^{a}$ Vivek R. Sanghani ${ }^{a} \quad$ Mitzie Spainhour $^{a}$ \\ Angelina W. Graham ${ }^{b}$ Gregory B. Russell ${ }^{c}$ Jessica N. Cooke Bailey ${ }^{f}$ \\ Ana S. Iltis ${ }^{d}$ Nancy M.P. King ${ }^{e}$

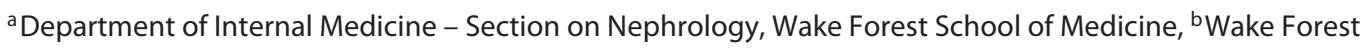 \\ Out-Patient Dialysis Program, 'Department of Biostatistical Sciences, Wake Forest School of Medicine, \\ ${ }^{\mathrm{d}}$ Department of Philosophy and Center for Bioethics, Health and Society, Wake Forest University, ${ }^{e}$ Division of \\ Public Health Sciences, Wake Forest School of Medicine, and Center for Bioethics, Health and Society, Wake Forest \\ University, Winston-Salem, N.C., and ${ }^{\mathrm{f} C e n t e r}$ for Human Genetics Research, Vanderbilt University Medical Center, \\ Nashville, Tenn., USA
}

\section{Key Words}

African-Americans · Bioethics · Kidney disease .

European-Americans $\cdot$ Genetic testing $\cdot$ Risk prediction

\begin{abstract}
Background: Population ancestry-based differences exist in genetic risk for many kidney diseases. Substantial debate remains regarding returning genetic test results to participants. African-Americans (AAs) and European-Americans (EAs) at risk for end-stage kidney disease were queried for views on the value and use of genetic testing in research. Methods: A standardized survey regarding attitudes toward genetic testing was administered to 130 individuals (64 AA, 66 EA) with first-degree relatives on dialysis. Fisher's exact test was used to assess differences in participant attitudes between population groups. Results: Mean (SD) age of surveyed AAs and EAs was 45.5 (12.8) and 50.5 (14.4) years, respectively $(p=0.04)$, with similar familial relationships ( $p=$ 0.22). AAs and EAs wished to know their test results if risk could be: (1) reduced by diet or exercise (100 and 98\%, $p=$ 0.99); (2) reduced by medical treatment (100 and 98\%, $\mathrm{p}=$ 0.99), or (3) if no treatments were available (90 and $82 \%, p=$
\end{abstract}

0.21). If informed they lacked a disease susceptibility variant, $87 \%$ of AAs and $88 \%$ of EAs would be extremely or pretty likely to inform family members $(p=0.84)$. If informed they had a disease susceptibility variant, $92 \%$ of AAs and $89 \%$ of EAs would be extremely or pretty likely to inform their family $(p=0.43)$. Conclusions: Attitudes toward obtaining and using genetic test results for disease in research contexts were similar in AAs and EAs at risk for end-stage kidney disease. A substantial majority would want information regardless of available treatments and would share the information with the family. These results have important implications for patient care, study design and the informed consent process.

(c) 2013 S. Karger AG, Basel

\section{Introduction}

It is increasingly possible to estimate disease risk based upon variation in an individual's genome. Although many genetic variants retain similar frequencies and effect sizes across populations of different ancestries, this is not uniformly the case. Several common disorders, in-

\section{KARGER}

(C) 2013 S. Karger AG, Basel

0250-8095/13/0386-0453\$38.00/0
Barry I. Freedman, MD

Section on Nephrology, Wake Forest School of Medicine

Medical Center Boulevard

Winston-Salem, NC 27157-1053 (USA)

E-Mail karger@karger.com
www.karger.com/ajn 
cluding osteoporosis, kidney disease, and coronary artery disease, demonstrate population ancestry-specific risk that is, in part, biologically mediated [1].

Non-diabetic kidney diseases are important examples of a common disease with differential risk across ethnic groups [2-4]. African-Americans (AAs) develop endstage kidney disease (ESKD) requiring dialysis or kidney transplantation nearly four times more often than European-Americans (EAs) [5]. Two coding variants in the apolipoprotein L1 gene (APOL1) account for the marked ethnic disparity in risk for non-diabetic nephropathy in African ancestry populations, relative to European ancestry populations $[2,3,6]$. Population ancestry-based differences are also seen in genetic risk for IgA nephropathy, partially accounting for worldwide variation in risk [2-4].

There is much discussion in the literature regarding the permissibility or impermissibility of returning genetic test results to research participants, and the obligation to share results [7]. Attitudes among groups of different population ancestry regarding research participation in general [8-11], participation in genetic research [12], genetic testing [13-15], return of genetic research results $[12,16-18]$, and family involvement in healthcare decisions [19] have been discussed. Research participants' perceptions regarding receiving (and sharing) information on genetic risk variants for disease obtained in a research study may differ based on population ancestry. This is an area that would benefit from additional study. Since ESKD strongly aggregates in families in all population groups, and coding variants in APOL1 contribute to the majority of cases of non-diabetic kidney disease in African ancestry populations, we queried AA and EA first-degree relatives of patients with ESKD for their opinions regarding receiving personal genetic data obtained in a research setting and on sharing those results with family members. This study sample offers a unique perspective because respondents know that they are at risk for a disease with a significant genetic component. Because there has been much speculation regarding differences in attitudes regarding genetic testing and research participation among AAs and EAs, we included these two groups in our study.

\section{Methods}

\section{Study Population}

First-degree relatives of self-reported AA and EA patients at Wake Forest Baptist Health outpatient dialysis facilities who had ESKD and who were performing in-center hemodialysis or home peritoneal dialysis were asked to participate in a voluntary survey (online suppl. fig. 1; for all online supplementary material, see www.karger.com/doi/10.1159/000356244). Parents, adult (>18 years) siblings and adult children of patients with ESKD were informed that the survey was designed to determine how they would use genetic information regarding disease susceptibility. Non-AA and non-EA family members were excluded due to their small numbers. No mention was made of either kidney disease or APOL1. Interviewers were trained before administering the survey (by N.M.P.K.) in order to provide a standardized interview process.

Survey administration took approximately $10 \mathrm{~min}$ in person or by telephone. For relatives of home peritoneal dialysis patients, surveys were personally administered by one of two dialysis nurses at a home dialysis training facility during regularly scheduled monthly clinic visits. For relatives of patients performing in-center hemodialysis, surveys were administered via telephone by one of two physicians.

The approach for assessing interest among potential survey respondents was scripted, and the script, study, and survey instrument were approved by the institutional review board (IRB) at the Wake Forest School of Medicine (online suppl. fig. 1). Contact information for subjects who declined participation was destroyed. Since this research presented no more than minimal risk of harm to participants and did not involve a procedure, a waiver of the requirement for signed informed consent was approved for telephone surveys. In-person respondents were asked to sign an information fact sheet that contained relevant information necessary for them to make an informed decision about participation. Online supplementary figure 1 contains the approach script and full survey.

\section{Statistical Analysis}

Frequencies and proportions were calculated for categorical study measures, with mean and standard deviation (SD) generated for age of the participants. To assess the difference in participant familial groupings and attitudes regarding genetic test results between the AA and EA subjects, Fisher's exact test was applied.

\section{Results}

Standardized questionnaires were administered to 64 AA and 66 EA individuals at increased risk for development of kidney disease based on having a first-degree relative with ESKD. The majority of respondents were unrelated, except in two EA families (one with 2 and one with 3 participating adult children) and three AA families (each with 2 participating adult children). The mean (SD) age of surveyed relatives was 45.5 (12.8) and 50.5 (14.4) years for AA and EA, respectively $(\mathrm{p}=0.04)$; this parallels the younger age at ESKD in AA patients relative to EA patients. Similar familial relationship groupings were seen between AA and EA participants and ESKD probands in families. For EA participants, $61 \%$ were adult children, $18 \%$ parents and $21 \%$ siblings and for AA participants, $45 \%$ were adult children, $23 \%$ parents and $31 \%$ 
siblings ( $\mathrm{p}=0.22$ for differences between AA and EA proband groups).

AA and EA participants, respectively, wished to know the results of their genetic tests if disease risk: (1) could be reduced by either diet or exercise (100 and $98 \%$ yes for survey question A.1, p = 0.99); (2) could be reduced by physician-directed treatment (100 and $98 \%$ yes for question A.2, p = 0.99), or (3) could not be reduced by known treatments (90 and $82 \%$ yes for question A.3, p = 0.21).

Participants were also asked to provide reasons for their answers. They could choose one or more of a set of four scripted reasons, and/or add their own comments. Approximately half of those who wanted to know their test results when there were known ways to lower their disease risk chose all of the scripted reasons: 'I just want to know health information about myself; 'I can use this information to improve my health'; 'I have the right to information about me', and 'I can use this information to plan ahead'. The reason cited most often, by well over $80 \%$ of all participants, was 'I can use this information to improve my health'. When there was no known way to lower risk, those who wanted their test results most often chose 'I just want to know information about myself and 'I can use this information to plan ahead'. Fewer participants chose all four reasons; about the same number chose only one reason. The few participants who did not want to know their test results if nothing were known that could lower their disease risk most often chose as reasons 'I worry that information like this could hurt me' and/or 'I don't think I could improve my health with this information'. Only 1 participant volunteered additional comments.

If informed that they did not possess a disease susceptibility variant, $87 \%$ of AA and $88 \%$ of EA would be 'extremely likely' or 'pretty likely' to inform the family of test results (question C.1; $\mathrm{p}=0.84$ ). If informed that they had a disease risk variant, $92 \%$ of AA and $89 \%$ of EA would be extremely likely or pretty likely to inform the family of test results (question C.2; $\mathrm{p}=0.43$ ).

The initial survey tool did not ask respondents to quantify the degree of risk they understood as 'high'. We therefore received Wake Forest IRB approval to re-contact a subset of $10 \%$ of participants by phone using a short script (online suppl. fig. 2) to precisely determine how they interpreted high risk (6 AA and 6 EA participants were re-contacted). AA participants responded that high risk reflected a mean $20.2 \%$ risk of disease (range 1-50\%) and EA participants responded that high risk reflected a mean $28.5 \%$ risk of disease (range $1-40 \%$ ).

Perceptions Regarding Genetic Testing

\section{Discussion}

This exploratory analysis assessed attitudes, in family members at high risk for developing a chronic disease, about obtaining, using, and sharing genetic test results acquired in a research context. Remarkably similar attitudes toward use of personal genetic data were seen in both AA and EA participants. Both population ancestral groups generally appeared to be very interested in obtaining, using and sharing genetic test results indicating the presence or absence of increased susceptibility to unspecified disease. This study demonstrates that a substantial majority of people with a close relative having ESKD would want genetic susceptibility information obtained in a research context regardless of the availability of prevention or treatment options, and that they would share this information with their families. Similar numbers of respondents said that they were highly likely to inform their families of genetic testing results whether or not they learned they had a genetic variant that increased disease susceptibility. This may reflect a high degree of awareness of the implications of genetic disease for close relatives.

This study provides important information about how particular population groups think about access to genetic information, and highlights the desirability of providing extensive information about genetic testing. Results suggest the importance of careful study design and disclosure regarding return of genetic test results in research studies. It is important for researchers and IRBs to consider the importance research participants place on receiving genetic test results. If researchers and IRBs agree that results should not be shared, they should recognize that participants might consider this to reduce the value of a study. Researchers may be reluctant to provide genetic testing results to participants because it is often unclear how accurate or informative preliminary genetic results are and whether they will replicate; however, there is increasing evidence that participants find value in them nonetheless [20]. Thus, if genetic test results will not be returned, researchers should ensure that participants understand and accept that they will not receive their research results even if they request and want them, and if researchers decide to share genetic test results, it will be important that they explain clearly to participants what those results mean and how much remains unknown about their presence. Initial genetic association results may subsequently prove to be false positive findings. Even highly significant and replicated results have changed in follow-up analyses. This was the case for the non-muscle myosin heavy chain 9 gene (MYH9) associa-

Am J Nephrol 2013;38:453-457

DOI: $10.1159 / 000356244$
455 
tion with non-diabetic forms of ESKD in AAs, a finding that was later proven to be the result of linkage disequilibrium between $\mathrm{MYH} 9$ and two coding variants in the adjacent APOL1 gene [6, 21, 22]. Findings such as this urge caution on the part of IRBs and investigators before providing preliminary genetic test results to participants in research studies. The majority of participants in this study preferred to be informed of their genetic test results obtained in research. IRBs should consider allowing return of results of replicated findings to study participants only with the caveat that scientific findings may evolve over time, interpretation of initial results may change, and therefore the attributable risk of disease based on initial findings may change based on future studies.

A limitation was the small sample size in this pilot study. Surveys were administered in the fall of 2012 during a presidential campaign and it was felt that some families may have refused to participate by telephone due to competing phone calls from political organizations. An advantage of the design was that family index cases were receiving nephrology care from two large nephrology practices with a total of more than 20 nephrologists, one an academic practice and one a private practice. As such, participating relatives' choices were unlikely to have been affected by their relative's physician and results can probably be generalized to similar families with members having ESKD.

The fact that study respondents knew they were selected because they have a close relative with ESKD may have influenced their survey responses, and thus the generalizability of these results beyond this population. Even though we were careful to make the survey questions in- tentionally non-specific about the nature of the genetic disease being studied in the hypothetical scenario, it remains possible that since subjects were told they were contacted as family members of dialysis patients, they may have had ESKD in mind as the disease in question. However, none of the index cases with ESKD or participating relatives were involved in ongoing genetic analyses of risk for ESKD at Wake Forest, so the likelihood that they had a particular degree of risk for ESKD in mind seems low. Nonetheless, this population may have a heightened sense of the significance of genetic risk factors compared with the general public. The mean results from the re-contacted subsample suggested that AAs and EAs felt an approximate $20-30 \%$ risk for disease reflected their perception of high risk. Extension of this research to other populations would be informative on this point.

In conclusion, although there is considerable debate about what role participants' preferences should play in deciding whether to disclose individual research results [23], knowing that participants feel strongly about having access to their results is instructive. It would be useful to know how other populations, including individuals who are not at increased risk for a disease with a genetic component, understand the desirability of receiving genetic test results obtained in research settings.

\section{Acknowledgements}

The authors report no conflicts of interest in this work. We thank Nephrology Associates and participating family members for their cooperation. This project was supported, in part, by NIH RO1 DK070941 and DK084149 (B.I.F.).

\section{References}

1 Freedman BI, Divers J, Palmer ND: Population ancestry and genetic risk for diabetes and kidney, cardiovascular, and bone disease: modifiable environmental factors may produce the cures. Am J Kidney Dis 2013 pii: S0272-6386(13)00979-7. doi: 10.1053/j.ajkd. 2013.05.024 (E-pub ahead of print).

$\nabla_{2}$ Genovese G, Friedman DJ, Ross MD, Lecordier L, Uzureau P, Freedman BI, Bowden DW, Langefeld CD, Oleksyk TK, Uscinski Knob AL, Bernhardy AJ, Hicks PJ, Nelson GW, Vanhollebeke B, Winkler CA, Kopp JB, Pays E, Pollak MR: Association of trypanolytic ApoL1 variants with kidney disease in African-Americans. Science 2010;329:841-845.

- 3 Tzur S, Rosset S, Shemer R, Yudkovsky G, Selig S, Tarekegn A, Bekele E, Bradman N, Wasser WG, Behar DM, Skorecki K: Missense mutations in the APOL1 gene are highly associated with end-stage kidney disease risk previously attributed to the $\mathrm{MYH} 9$ gene. Hum Genet 2010;128:345-350.

-4 Kiryluk K, Li Y, Sanna-Cherchi S, Rohanizadegan M, Suzuki H, Eitner F, Snyder HJ, Choi M, Hou P, Scolari F, Izzi C, Gigante M, Gesualdo L, Savoldi S, Amoroso A, Cusi D, Zamboli P, Julian BA, Novak J, Wyatt RJ, Mucha K, Perola M, Kristiansson K, Viktorin A, Magnusson PK, Thorleifsson G, Thorsteinsdottir U, Stefansson K, Boland A, Metzger M, Thibaudin L, Wanner C, Jager KJ, Goto S, Maixnerova D, Karnib HH, Nagy J, Panzer U, Xie J, Chen N, Tesar V, Narita I, Berthoux F, Floege J, Stengel B, Zhang H, Lifton RP, Gharavi AG: Geographic differences in genetic susceptibility to IgA nephropathy: GWAS replication study and geospatial risk analysis. PLoS Genet 2012;8:e1002765.

5 US Renal Data System, USRDS 2012 Annual Data Report, vol 1: Atlas of chronic kidney disease and end-stage renal disease in the United States. Bethesda, National Institutes of Health, National Institute of Diabetes and Digestive and Kidney Diseases, 2012.

-6 Freedman BI, Kopp JB, Langefeld CD, Genovese G, Friedman DJ, Nelson GW, Winkler CA, Bowden DW, Pollak MR: The apolipoprotein L1 (APOL1) gene and nondiabetic nephropathy in African-Americans. J Am Soc Nephrol 2010;21:1422-1426.

7 O'Daniel J, Haga SB: Public perspectives on returning genetics and genomics research results. Public Health Genomics 2011;14:346355. 
8 Buchwald D, Mendoza-Jenkins V, Croy C, McGough H, Bezdek M, Spicer P: Attitudes of urban American Indians and Alaska Natives regarding participation in research. J Gen Intern Med 2006;21:648-651.

9 Farmer DF, Jackson SA, Camacho F, Hall MA: Attitudes of African-American and low socioeconomic status White women toward medical research. J Health Care Poor Underserved 2007; 18:85-99.

10 Corbie-Smith G, Thomas SB, Williams MV, Moody-Ayers S: Attitudes and beliefs of African-Americans toward participation in medical research. J Gen Intern Med 1999;14:537546.

11 Wendler D, Kington R, Madans J, Van WG, Christ-Schmidt H, Pratt LA, Brawley OW, Gross CP, Emanuel E: Are racial and ethnic minorities less willing to participate in health research? PLoS Med 2006;3:e19.

$\checkmark 12$ Streicher SA, Sanderson SC, Jabs EW, Diefenbach M, Smirnoff M, Peter I, Horowitz CR, Brenner B, Richardson LD: Reasons for participating and genetic information needs among racially and ethnically diverse biobank participants: a focus group study. J Community Genet 2011;2:153-163.
13 Jonassaint CR, Santos ER, Glover CM, Payne PW, Fasaye GA, Oji-Njideka N, Hooker S, Hernandez W, Foster MW, Kittles RA, Royal $\mathrm{CD}$ : Regional differences in awareness and attitudes regarding genetic testing for disease risk and ancestry. Hum Genet 2010;128:249260.

14 Singer E, Antonucci T, Van HJ: Racial and ethnic variations in knowledge and attitudes about genetic testing. Genet Test 2004;8:3143.

15 Laskey SL, Williams J, Pierre-Louis J, O’Riordan M, Matthews A, Robin NH: Attitudes of African-American premedical students toward genetic testing and screening. Genet Med 2003;5:49-54.

16 Lemke AA, Halverson C, Ross LF: Biobank participation and returning research results: perspectives from a deliberative engagement in South Side Chicago. Am J Med Genet A 2012;158A:1029-1037.

17 Halverson CM, Ross LF: Attitudes of AfricanAmerican parents about biobank participation and return of results for themselves and their children. J Med Ethics 2012;38:561-566.

$18 \mathrm{Yu}$ JH, Crouch J, Jamal SM, Tabor HK, Bamshad MJ: Attitudes of African-Americans toward return of results from exome and whole genome sequencing. Am J Med Genet A 2013; 161A:1064-1072.

19 Kwak J, Haley WE: Current research findings on end-of-life decision-making among racially or ethnically diverse groups. Gerontologist 2005;45:634-641.
20 Bollinger JM, Scott J, Dvoskin R, Kaufman D: Public preferences regarding the return of individual genetic research results: findings from a qualitative focus group study. Genet Med 2012;14:451-457.

21 Kopp JB, Smith MW, Nelson GW, Johnson RC, Freedman BI, Bowden DW, Oleksyk T, McKenzie LM, Kajiyama H, Ahuja TS, Berns JS, Briggs W, Cho ME, Dart RA, Kimmel PL, Korbet SM, Michel DM, Mokrzycki MH, Schelling JR, Simon E, Trachtman H, Vlahov D, Winkler CA: $M Y H 9$ is a major-effect risk gene for focal segmental glomerulosclerosis. Nat Genet 2008;40:1175-1184.

22 Kao WH, Klag MJ, Meoni LA, Reich D, Berthier-Schaad Y, Li M, Coresh J, Patterson N, Tandon A, Powe NR, Fink NE, Sadler JH, Weir MR, Abboud HE, Adler SG, Divers J, Iyengar SK, Freedman BI, Kimmel PL, Knowler WC, Kohn OF, Kramp K, Leehey DJ, Nicholas SB, Pahl MV, Schelling JR, Sedor JR, Thornley-Brown D, Winkler CA, Smith MW, Parekh RS: $M Y H 9$ is associated with nondiabetic end-stage renal disease in AfricanAmericans. Nat Genet 2008;40:1185-1192.

23 Parker LS: Returning individual research results: what role should people's preferences play? Minn J Life Sci Tech 2012;13:449-484. 